\title{
Spontaneous splenic rupture, an unusual presentation of tuberculosis
}

\author{
Ruptura esplénica espontánea, una presentación inusual de tuberculosis
}

Edson R. Marcos-Ramírez*, Luis A. Treviño-García, Alejandra Téllez-Aguilera, Max Molina-Ayala, Juan P. Flores-Gutiérrez, Rogelio Salinas-Domínguez, and Gerardo E. Muñoz Maldonado

Service of General Surgery, Hospital Universitario "Dr. José Eleuterio González”, Universidad Autónoma de Nuevo León, Monterrey, Nuevo Leon, Mexico

\begin{abstract}
Introduction: Spontaneous splenic rupture from tuberculosis (TB) is a very unusual presentation within the wide range of presentations of this infectious disease. Clinical case: A 40-year-old male with a diagnosis of human immunodeficiency virus, begins with fever and pain in the left hypochondrium. A computed tomography scan was performed, showing probable splenic abscesses; suddenly, it begins with hemodynamic deterioration, exacerbation of pain, a surgical exploration was performed, showing spontaneous splenic rupture. Microscopic study of the spleen shows the presence of Mycobacterium tuberculosis. Conclusions: This is yet another presentation of TB, which can become a surgical emergency.
\end{abstract}

Key words: Tuberculosis. Extrapulmonary. Rupture. Spleen. Spontaneous.

\section{Resumen}

Introducción: La ruptura esplénica espontánea por tuberculosis es una presentación muy inusual dentro de la amplia gama de presentaciones de esta enfermedad infectocontagiosa. Caso clínico: Masculino de 40 años con diagnóstico de VIH, inicia con fiebre y dolor en hipocondrio izquierdo. Se realiza TAC evidenciando probables abscesos esplénicos; súbitamente comienza con deterioro hemodinámico, agudización del dolor, se realiza exploración quirúrgica evidenciando ruptura esplénica espontánea. Al estudio microscópico del bazo se observa presencia de Mycobacterium Tuberculosis. Conclusiones: Esta es una presentación más de la TB, la cual puede convertirse en una urgencia quirúrgica.

Palabras clave: Tuberculosis. Extrapulmonar. Ruptura. Bazo. Espontáneo.

\section{Introduction}

Tuberculosis (TB) continues to be a mayor health issue around the world despite advances in its diagnosis and treatment. This disease presents with an important clinical diversity, a characteristic that makes TB a challenge for the treating physician, whether clinical or surgical. Within this diversity, we can classify its presentation in pulmonary and extrapulmonary TB, the latter being the one that covers only $15 \%$ of all diagnosis'.

\section{Correspondence:}

*Edson R. Marcos-Ramírez

Avda. Francisco I Madero, S/N

Col. Mitras Centro

Date of reception: 13-07-202

C.P.: 64460 , Monterrey, N.L., México

E-mail: ermarcos7@gmail.com
Cir Cir. 2021;89(S1):1-5

Contents available at PubMed www.cirugiaycirujanos.com
of the CC BY-NC-ND license (http://creativecommons.org/licenses/by-nc-nd/4.0/). 
Extrapulmonary TB with abdominal origin is a rare condition in western countries, despite this, a resurgence of the disease has been observed in recent years in developed countries due to the increase in the frequency of immunodeficiency state cause mostly by human immunodeficiency virus (HIV) ${ }^{1}$. In spite of the fact that the presence of pulmonary TB can be associated with abdominal TB, only $15 \%$ of patients with abdominal TB have accurate evidence of pulmonary $\mathrm{TB}^{2}$, this is relevant because it is these cases that become a greater challenge for its diagnosis and management. Of the organs and tissues involved in abdominal TB, splenic involvement has been reported in cases of disseminated TB, where immunosuppression is significant ${ }^{3}$, while its isolated involvement remains an unusual entity ${ }^{3-5}$. Risk factors for splenic TB include immunosuppression, previous pyogenic splenic infections, a history of splenic trauma ${ }^{6}$.

We presented a case of a male with fever of origin to determine to whom the presence of probable splenic abscesses is radiographically evidenced, later the patient suffers sudden clinical deterioration due to spontaneous splenic rupture.

\section{Clinical case}

We present the case of a 40-year-old male with no relevant history, who went to the ER for reporting fever of 2 months of evolution, intermittent, predominantly daytime, with maximum peaks recorded of $40^{\circ} \mathrm{C}$, accompanied by asthenia, adynamia, loss of unintentional weight of about $5 \mathrm{~kg}$ in the past 2 months, and denied any other history.

During the initial evaluation, the patient was found to be feverish, tachycardia, with normal blood pressure, without integument pallor, or jaundice. On physical examination, the lung fields were auscultated without consolidating any pleuro-pulmonary syndrome, normal heart sounds without the presence of murmurs; on abdominal palpation, he found slight pain in the left hypochondrium, with no evidence of peritoneal irritation, in addition to the presence of Grade 1 splenomegaly without hepatomegaly, the rest of the examination without relevant data.

Within laboratory tests, the initial blood count showed a hemoglobin at $12.1 \mathrm{~g} / \mathrm{dL}$, leukocytes at $6.32 \mathrm{k} / \mathrm{uL}$, neutrophils at $5.70 \mathrm{k} / \mathrm{uL}$, lymphocytes at $0.448 \mathrm{k} / \mathrm{uL}$, platelets at $147 \mathrm{k} / \mathrm{uL}$, a preserved function of the kidney with serum creatinine of $0.8 \mathrm{mg} / \mathrm{dL}$, and a slight increase in liver enzymes: aspartate aminotransferase $145 \mathrm{IU} / \mathrm{L}$, alanine aminotransferase $99 \mathrm{IU} / \mathrm{L}$, alkaline phosphatase $139 \mathrm{IU} / \mathrm{L}$, in addition to total bilirubin $1.6 \mathrm{mg} / \mathrm{dL}$, direct bilirubin $0.5 \mathrm{mg} / \mathrm{dL}$, indirect at $1.1 \mathrm{mg} / \mathrm{dL}$, and general urine test within normal limits. His initial chest and abdominal radiographs were observed without relevant data.

Viral serology was requested by immunoassay, being positive for HIV, so GeneXpert was performed detecting HIV-1 with a viral load of $3,260,000$ copies $/ \mathrm{mL}$, with an absolute CD4 count of $66 \mathrm{c} / \mu \mathrm{L}$. Samples were taken for blood culture which was negative for bacteria and fungi, including ZiehlNeelsen and potassium hydroxide tests on sputum, intradermal reaction test for tuberculin (Purified Protein Derivative), coccidioidin and candidin, Venereal Disease Research Laboratory in blood and cerebrospinal fluid, which were negative.

His study was complemented with a computed axial tomography (CT) of the chest and contrast abdomen where the lung parenchyma was observed without the presence of infiltrates or pleural effusion, without cavitated lesions or the presence of mediastinal lymph nodes; in the abdomen, data of hepatic steatosis and splenomegaly of $13.6 \mathrm{~cm}$ were observed, associated with multiple hypodense images of diffuse distribution, the largest being $2.2 \mathrm{~cm}$ in diameter, suggesting multiple splenic abscesses (Fig. 1). Due to the presence of these images and the persistence of the clinical picture, it was planned to perform a splenectomy by laparoscopy, however, during the pre-operative period the patient presented sudden deterioration in his vital signs, required supplemental oxygen, tachycardia at $140 \mathrm{bpm}$, and hypotensive with $80 / 60 \mathrm{mmHg}$, which led to hemodynamic resuscitation based on crystalloids and blood products, which stabilized the patient. On exploring the abdomen, distention and stiffness were found, with evidence of frank peritoneal irritation. Given this scenario, it was decided to urgently enter the operating room; the left subcostal approach was started finding $500 \mathrm{cc}$ of hemoperitoneum located in the left upper quadrant, the spleen was observed with the presence of multiple pinpoint whitish lesions in its parenchyma, in addition to the presence of active bleeding secondary to a Grade V injury. Vascular control of the splenic hilum was performed to perform the splenectomy, the rest of the abdominal cavity was normal. In figure 2 , we can see the surgical piece resulting from the splenectomy.

During his immediate postoperative period, he continued to require vasopressors, so he went to the intensive care unit to continue his recovery. $\mathrm{He}$ 

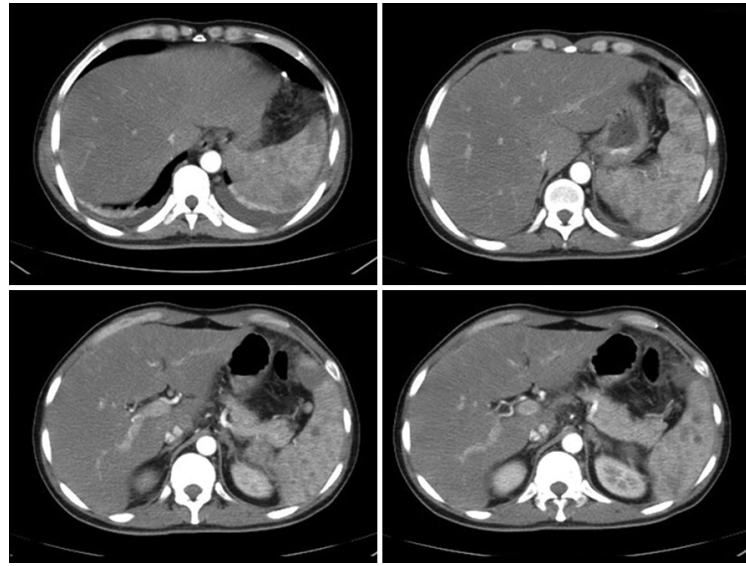

Figure 1. Computed tomography of the abdomen where multiple hypodense lesions with diffuse distribution are observed in the splenic parenchyma, suggestive of splenic abscesses.

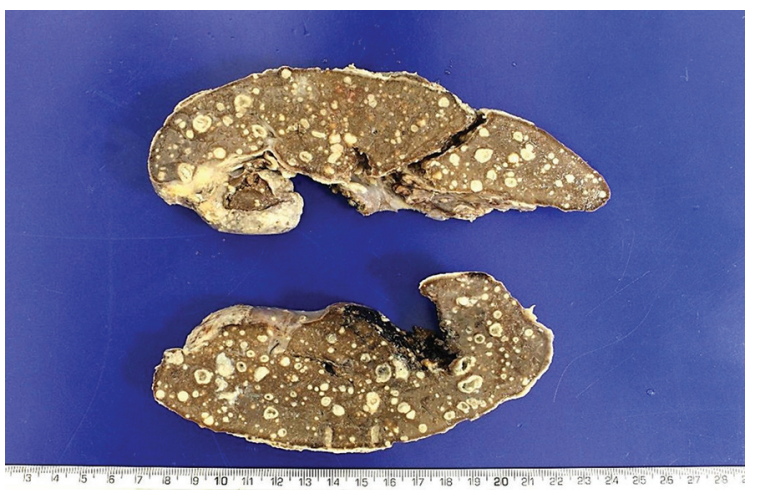

Figure 2. Product of splenectomy, we observe the rupture of the splenic parenchyma in addition to the whitish nodular lesions throughout the spleen.

presented hemodynamic and clinical improvement to the $10^{\text {th }}$ post-operative day, so he continued his in-hospital management at the general hospital ward.

The histopathological report of the spleen reported a chronic granulomatous inflammatory process associated with the presence of acid-resistant bacilli (Fig. 3). GeneXpert was performed for Mycobacterium tuberculosis with a positive result and no resistance detected for rifampicin, so antifimic therapy based on rifampicin $150 \mathrm{mg}$, isoniazid $75 \mathrm{mg}$, pyrazinamide $400 \mathrm{mg}$, and ethambutol $300 \mathrm{mg}$ in its intensive phase was started, responding favorably to treatment. Finally, and after 62 days of hospitalization, he was discharged with an outpatient follow-up.
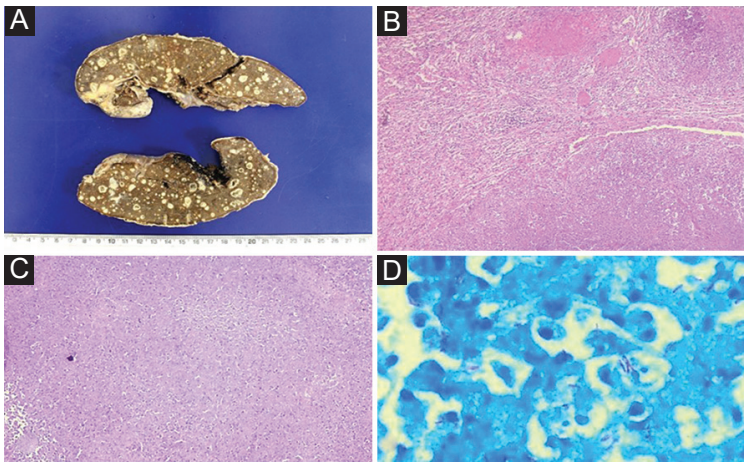

Figure 3. At multiple sections grade $V$ splenic rupture is evident, in addition to multiple well-circumscribed lesions. A: whitish brown in color and soft in consistency. B: on light microscopy, multiple granulomas. C: with a necrotic center were evident. D: Ziehl-Neelsen staining was positive for multiple acid-resistant bacilli.

\section{Discussion}

At present, it is estimated that 10 million people in the world (a range of 9-11 million) have been diagnosed with TB in 2018 alone, a number that has remained stable in recent years with a rate of 500 new cases for each 100,000 inhabitants per year; 251,000 deaths from HIV-positive TB are reported in these cases $^{7}$. In Mexico, TB is an important public health problem since the binomial TB-HIV is a common presentation in our population. Due to this association of diseases, the clinical presentations can be so varied that they become exceptional in different cases.

Clinically, TB presents as a pulmonary or extra pulmonary disease, the most frequent being the first presentation $^{8}$. Splenic TB is a singular and unusual case and can present itself in two ways: the first form is during miliary TB in immunocompromised patients, the spleen being the third most affected organ in miliary TB (100\% lung, $82 \%$ liver, spleen $75 \%$, lymph nodes $55 \%$, and bone marrow $41 \%)^{3-9}$. The second unusual way of presenting is primarily, as it was in our patient, with few reports in the past 20 years ${ }^{10}$. These cases were immunocompromised patients who started their symptoms with fever of origin to be determined, which is characteristic in the presentation of splenic TB ${ }^{11}$.

Primary splenic TB is presented as a case of hypersplenism, splenic abscess, or as a solitary splenic lesion. Its detected by contrasted CT that shows multiple hypodense nodulations in the splenic parenchyma; however, these can be characteristic of several conditions in addition to splenic TB such as cysts, 
hematomas, and fungal infections such as candidiasis, spleen infarctions, lymphoma, or metastasis ${ }^{12-14}$.

The diagnosis of splenic TB is complicated in patients without evidence of pulmonary involvement. Histopathological confirmation is required and this can be obtained in the first instance by means of a splenic biopsy, having an $88 \%$ sensitivity with fine-needle aspiration for the diagnosis of splenic $\mathrm{TB}^{15}$. The decision to perform a biopsy or go directly to splenectomy is entirely up to the doctor, depending on the conditions in which the patient is.

The histological findings of splenic TB are the same as those observed in the pulmonary presentation: the presence of granulomas with a necrotic center, surrounded by epithelioid histiocytes and a lymphocyte crown, either isolated or diffuse, together with the presence of bacilli acid-alcohol resistant in ZiehlNeelsen staining. The presence of giant Langhanstype cells is variable, and is not exclusive to this disease. Likewise, other infectious possibilities should be ruled out with this histological image, especially Coccidioides Spp infections in our setting.

The treatment described in the literature is based on anti-TB drugs without actually performing a splenectomy ${ }^{8}$, with them an adequate response is obtained at 6 months, similar to extrapulmonary TB from other sites due to the excellent penetration into tissues of this type of drugs. There are controlled clinical studies that recommend a duration of up to 12 months with the possible prolongation of treatment if necessary ${ }^{16}$. Due to the good response of the symptoms with anti-TB drugs, these remain the first line of the treatment for splenic TB and splenectomy is rarely required; however, surgical treatment is necessary if there is the formation of a splenic abscess, if the biopsy specimens do not show diagnostic results, when there is no response to treatment or when the patient's clinical conditions become critical, as it was in our patient ${ }^{17}$.

\section{Conclusions}

The spectrum of presentations of TB is very broad, and primary splenic TB is itself a very rare medical entity in an immunocompromised patient. The spontaneous rupture adds a greater singularity to the case due to the low frequency with which it is reported. In this case, a probable spontaneous splenic rupture was suspected clinically due to sudden clinical deterioration, which was confirmed in the operating room, this being a highly unusual surgical emergency reported in the literature. It is important to consider the extent of TB, since it is an entity that can start its management with medical treatment and close monitoring; however, conditions can become an emergency situation where surgical treatment will be the difference between life and death in this type of patient.

\section{Conflicts of interest}

The authors declare no conflicts of interest.

\section{Acknowledgment}

To the work team and the patients of our hospitalschool, who is the reason for our work.

\section{Ethical disclosures}

Protection of human and animal subjects. The authors declare that the procedures followed were in accordance with the regulations of the relevant clinical research ethics committee and with those of the Code of Ethics of the World Medical Association (Declaration of Helsinki).

Confidentiality of data. The authors declare that they have followed the protocols of their work center on the publication of patient data.

Right to privacy and informed consent. The authors have obtained the written informed consent of the patients or subjects mentioned in the article. The corresponding author is in possession of this document.

\section{References}

1. Al-Humadi HW, Al-Saigh RJ, Al-Humadi AW. Addressing the challenges of tuberculosis: a brief historical account. Front Pharmacol. 2017:8:1-10.

2. Manohar A, Simjee AE, Haffejee AA, Pettengell KE. Symptoms and investigative findings in 145 patients with tuberculous peritonitis diagnosed by peritoneoscopy and biopsy over a five year period. Gut. 1990;31:1130-32.

3. Imani Fooladi AA, Hosseini MJ, Azizi T. Splenic tuberculosis: a case report. Int J Infect Dis. 2009;13:273-5.

4. Azzam NA. Splenic tuberculosis presenting as fever of unknown origin with severe neutropenia. Ann Clin Microbiol Antimicrob. 2013;12:1.

5. Gupta P, Fotedar S, Agarwal D, Sansanwal P. Tuberculosis of spleen presenting with pyrexia of unknown origin in a non-immunocompromised woman. Lung India. 2008;25:22.

6. Basa J V, Singh L, Jaoude WA, Sugiyama G. A case of isolated splenic tuberculosis. Int J Surg Case Rep. 2015;8:117-9.

7. World Health Organization. Global Tuberculosis Report. Geneva: World Health Organization; 2019

8. Velásquez Morales J, Szigethi QM, Panace R. Micobacteriosis hepato-esplénica, forma inusual de probable tuberculosis extrapulmonar. Caso clínico y revisión bibliográfica. Rev Chil Infectol. 2007;24:59-62.

9. Abebe G, Zegeye Bonsa WK. Treatment outcomes and associated factors in tuberculosis patients at Jimma University Medical Center: a 5year retrospective study gemeda. Int J Mycobacteriol. 2017;6:239-45.

10. Agarwala S, Bhatnagar V, Mitra DK, Gupta AK, Berry M. Primary tubercular abscess of the spleen. J Pediatr Surg. 1992;27:1580-1. 
11. Bastounis E, Pikoulis E, Varelas $P$, Cirochristos DA. Tuberculoma of the spleen: a rare but important clinical entity. Am Surg. 1999;65:131-2.

12. Tang TQ, Hsu YH, Lee JJ. Disseminated tuberculosis with splenic tuberculosis abscess rupture: a rare presentation. Am J Respir Crit Care Med. 2014;190:829-30.

13. Pereira JM, Madureira AJ, Vieira A, Ramos I. Abdominal tuberculosis: imaging features. Eur J Radiol. 2005;55:173-80.

14. Kundu PR, Mathur SK, Singh S, Duhan A, Aggarwal G, Sen R. Isolated tuberculous splenic abscess in an immunocompetent individual. Asian Pac J Trop Med. 2011;4:81-2.
15. Suri R, Gupta S, Gupta SK, Singh K, Suri S. Ultrasound guided fine needle aspiration cytology in abdominal tuberculosis. $\mathrm{Br} \mathrm{J}$ Radiol. 1998;71:723-7.

16. Hamizah R, Rohana AG, Anwar SA, Ong TZ, Hamzaini AH, Zulkarnaen AN. Splenic tuberculosis presenting as pyrexia of unknown origin. Med J Malaysia. 2007;62:70-1.

17. Nayyar V, Ramakrishna B, Mathew G, Williams RR, Khanduri P. Response to antituberculous chemotherapy after splenectomy. J Intern Med. 1993;233:81-3. 